\title{
STABILITY-INDICATING RP-HPLC METHOD FOR ANALYSIS OF ATORVASTATIN IN BULK DRUG, MARKETED TABLET AND NANOEMULSION FORMULATION
}

\author{
GULAM MUSTAFA', ADNAN AZEEM ${ }^{1 *}$, FARHAN J. AHMAD ${ }^{l}$, ZEENAT I. KHAN ${ }^{1}$, \\ FAIYAZ SHAKEEL ${ }^{2}$ AND SUSHMA TALEGAONKAR ${ }^{1}$
}

\author{
${ }^{\prime}$ Department of Pharmaceutics, Faculty of Pharmacy, Jamia Hamdard, Hamdard Nagar; New Delhi-110062, India \\ ${ }^{2}$ Department of Pharmaceutics, Faculty of Pharmacy, Al-Arab Medical University, Benghazi, Libya
}

(Received: May 8, 2009 - Accepted: July 22, 2009)

\begin{abstract}
A simple, highly sensitive, isocratic stability indicating reversed phase-high performance liquid chromatography (RP-HPLC) method with UV detection at $247 \mathrm{~nm}$ was developed and validated for analysis of atorvastatin (AT). Retention time of the AT was found to be 4.02 min. A mobile phase consisting of $0.05 \mathrm{M}$ sodium phosphate buffer and methanol $(3: 7 \mathrm{v} / \mathrm{v}) \mathrm{pH} 4.1$ at flow rate of $1 \mathrm{~mL} / \mathrm{min}$ was employed in this study. The calibration curves were linear with regression coefficient $\left(\mathrm{r}^{2}\right)$ of $0.9997 \pm 0.0014$. The limits of detection (LOD) and the limits of quantification (LOQ) were found to be 0.20 and $0.60 \mu \mathrm{g} / \mathrm{mL}$, respectively. The method was statistically validated in accordance with International conference on harmonization (ICH) guidelines. The proposed method was found sensitive, specific and was successfully applied for the estimation of atorvastatin in pharmaceutical formulations (bulk drug, tablet, nanoemulsion).
\end{abstract}

Keywords: RP-HPLC; atorvastatin; nanoemulsion; tablets; ICH guidelines.

\section{INTRODUCTION}

Atorvastatin (AT) is chemically described as $\left[\mathrm{R}-\left(\mathrm{R}^{*}, \mathrm{R}^{*}\right)\right]-2-(4-$ fluorophenyl)- dihydroxy-5- (1- methylethyl)-3-phenyl-4-[(phenylamino) carbonyl]-1H-pyrrole heptanoic acid. ${ }^{1}$ It is demonstrated to be efficacious in the treatment of hyperlipidaemias (familial and non-familial) or combined hyperlipedemia by competitively inhibiting the rate-limiting enzyme, hydroxyl methyl glutaryl coenzyme A (HMG-CoA) reductase, involved in cholesterol biosynthesis. ${ }^{2}$ Although AT is absorbed rapidly after oral administration, it has low absolute bioavailability (about $12 \%$ ) due to high first pass metabolism. Considerable efforts have been directed towards improving its oral bioavailability by formulation approaches. Nanoemulsion is one of the most emerging drug delivery technologies to overcome the solubility and bioavailability related problems. ${ }^{3-5}$ The presence of multiple components may interfere with the drug analysis and low bioavailability (12\%) of atorvastatin (AT) make the analysis altogether more challenging. Therefore, a suitable and sensitive quantification method is required for determination of AT in both bulk drug as well as in pharmaceutical formulations.

Two spectrophotometric and one high performance thin layer chromatography (HPTLC) method is available for determination of AT in bulk drug and pharmaceutical formulations..$^{6-8}$ Many analytical methods have been reported for the determination of AT alone or in combination with other drugs using chromatographic methods..$^{1,9-25}$ Several HPLC methods using ultraviolet (UV) or mass spectrophotometric (MS) detection have also been reported for analytical determination of AT in biological fluids ${ }^{9-15,26-28}$ and commercial pharmaceutical products. ${ }^{1,11,16-23,29}$ But these methods may not always be suitable due to large investments. AT is a very common cholesterol lowering drug available in many commercial pharmaceutical products either alone or in combination with other drugs. Therefore we still need a simple and sensitive analytical method for determination of AT in bulk drug, commercial products and biological samples. Keeping this point into consideration, an attempt was made to develop a simple, sensitive and validated stability indicating RPHPLC method using UV detection for the estimation of AT in bulk drug. The applicability of the method was confirmed for analysis of AT in pharmaceutical products (tablets and nanoemulsion). The results of analysis were validated in

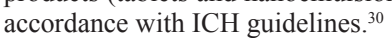

\section{EXPERIMENTAL}

\section{Materials}

AT calcium and diclofenac were obtained as a gift sample from Lupin Ltd. (Pune, India) and Arbro Pharmaceuticals (Delhi, India), respectively. HPLC grade methanol, sodium dihydrogen phosphate, sodium hydroxide, hydrochloric acid and hydrogen peroxide were purchased from E-Merck Ltd (Mumbai, India). AT calcium tablets ATORLIP-10® was obtained from Cipla
Limited (Mumbai, India). HPLC grade water (LiChrosolv $®$ ) was purchased from E-Merck Ltd (Mumbai, India) and was used to prepare all the solutions. All the other chemicals and reagents used were of AR grade and purchased from SD fine chemicals Ltd (Mumbai, India).

\section{Method development}

Various solvent systems were tried for the development of suitable HPLC method for the analysis of AT calcium in the pharmaceutical formulations. The suitability of the solvent system was decided on the basis of the sensitivity of the assay, suitability for stability studies and availability of cost effective solvents.

Preparation of stock and standard solutions

A stock solution of AT $(100 \mu \mathrm{g} / \mathrm{mL})$ was prepared by dissolving $50 \mathrm{mg}$ of the drug in $100 \mathrm{~mL}$ of methanol, further $2 \mathrm{~mL}$ of this solution was transferred to $10 \mathrm{~mL}$ volumetric flask and volume was made up to $10 \mathrm{~mL}$ with mobile phase to obtain $100 \mu \mathrm{g} / \mathrm{mL}$ concentrations. Different aliquots of the standard stock solution of AT were transferred into $10 \mathrm{~mL}$ volumetric flasks separately and the solutions were made up to $10 \mathrm{~mL}$ with mobile phase to yield a wide concentration range from 0.125 to $100 \mu \mathrm{g} / \mathrm{mL}$.

\section{Selection of analytical wavelength}

By appropriate dilution of standard stock solution with mobile phase, various concentrations of AT were prepared accurately. The solutions were scanned between the wavelength range of $400 \mathrm{~nm}$ to $200 \mathrm{~nm}$ using the Shimadzu double beam UV visible spectrophotometer in the spectrum mode.

HPLC instrumentation

The HPLC equipment consisted of quaternary LC-10A VP pump, SPD10AVP column oven, variable wavelength programmable UV/VIS detector, SCL 10AVP system controller, Rheodyne injector fitted with a $20 \mu \mathrm{L}$ loop, degasser and a data processor all from Shimadzu, Kyoto, Japan. Class-VP 5.032 software was used to record and evaluate the data collected during and following chromatographic analysis.

Method validation

The prepared dilutions were injected serially in reverse order and area under the peaks was calculated for each dilution. The method was validated for various parameters such as linearity, accuracy, precision, and specificity, limit of detection (LOD), limit of quantification (LOQ), robustness and ruggedness according to the ICH guidelines.

\section{Linearity}

Appropriate aliquots of drug were pipetted out from the standard stock solution into a series of $10 \mathrm{~mL}$ volumetric flasks. The volume was made up to the mark with mobile phase to obtain concentration levels of AT ranging from 0.125 to $100 \mu \mathrm{g} / \mathrm{mL}$. Triplicate dilutions of each concentration of drug were prepared separately and chromatographed under the optimized conditions. Analysis of drug was performed with the UV detector set at $247 \mathrm{~nm}$ and peak areas were recorded. The graph was plotted between concentration and area under peak for linearity. 


\section{Accuracy as recovery}

Accuracy was determined by recovery study of AT. The study was carried out at four different concentration levels. The known amounts of AT standard $(100 \mu \mathrm{g} / \mathrm{mL})$ i.e. $0(0 \%), 1(50 \%), 1.5(100 \%)$ and $2(150 \%) \mathrm{mL}$ were added into pre-analyzed $5 \mathrm{~mL}(10 \mu \mathrm{g} / \mathrm{mL})$ sample in four different $10 \mathrm{~mL}$ volumetric flasks respectively. Volume was then made up to $10 \mathrm{~mL}$ with mobile phase to get the resultant concentrations of $10,15,20$ and $25 \mu \mathrm{g} / \mathrm{mL}$ respectively and subjected them to the proposed HPLC method. The experiments were performed in triplicate. The recovery of sample, \% RSD and standard error were calculated at each concentration level.

Precision

Precision was studied to find out intra-day (repeatability) and inter-day (injecting the samples over three consecutive days) variations in the HPLC method at four different concentration levels (i.e. $0.05,0.5,5$ and $50 \mu \mathrm{g} / \mathrm{mL}$ ) in triplicate. The $\%$ RSD and standard error were calculated at each concentration level.

\section{Specificity}

The specificity of the method was determined by exposing a solution (10 $\mu \mathrm{g} / \mathrm{mL})$ of the sample to acidic $(0.1 \mathrm{M} \mathrm{HCl})$, basic $(0.1 \mathrm{M} \mathrm{NaOH})$ and oxidizing $\left(3 \% \mathrm{H}_{2} \mathrm{O}_{2}\right)$ stress conditions. The resulting solutions were then analyzed and the analyte peak was evaluated for peak purity and for resolution from the nearest eluting peak.

\section{Limit of detection (LOD) and limit of quantification (LOQ)}

Detection and quantification limits were calculated by the method based on standard deviation $\left(\mathrm{S}_{\mathrm{y} / \mathrm{x}}\right)$ of the responses for the blank injection in triplicate and the slope (S) of the calibration curve. The peak area of the blank was calculated. The LOD and LOQ were determined using slope of the calibration curve and standard deviation of the blank sample by following formulae:

$L O D=3.3 \times S y / x / S$

$L O Q=10 \times S y / x / S$

Here $\mathrm{S} \mathrm{y} / \mathrm{x}$ is the standard deviation of the blank response and $\mathrm{S}$ is the slope of the calibration curve.

\section{Robustness and ruggedness}

ICH guidelines were followed during the development of the analytical procedure. ${ }^{30}$ The robustness of the developed method was studied by making small deliberate changes in the chromatographic conditions at 3 different levels i.e. $-1,0,+1$ and retention time of AT was measured at each level. For the present study the chromatographic conditions selected were flow rate $(1.1 \mathrm{~mL} /$ $\mathrm{min}, 1.0 \mathrm{~mL} / \mathrm{min}$ and $0.9 \mathrm{~mL} / \mathrm{min}), \mathrm{pH}(4.0,4.1$, and 4.2$)$ and $\%$ methanol $(71$ $\%, 70 \%$ and $69 \%$ ) in the mobile phase. ${ }^{30-31}$

The ruggedness of the method was assessed by comparison of the intraand inter-day assay results of AT that have been performed by two analysts in the same laboratory.

\section{Stability studies}

To ensure the reliability of the results in relation to handling and storage of stock standard solutions, stability studies during the experimentation were performed at two different concentrations $[(1 \mu \mathrm{g} / \mathrm{mL}$ and $50 \mu \mathrm{g} / \mathrm{mL}$ in 0.05 $\mathrm{M}$ sodium phosphate buffer and methanol $(30: 70 \mathrm{v} / \mathrm{v}) \mathrm{pH} 4.1])$ by repeated analysis of the samples over a period of $72 \mathrm{~h}$ at ambient temperature $\left(32 \pm 2^{\circ} \mathrm{C}\right)$ and at the refrigerated temperature $\left(8 \pm 1{ }^{\circ} \mathrm{C}\right)$.

\section{Method application}

\section{Analysis of AT in marketed tablet}

To determine the content of AT in the tablet formulation, 20 Atorlip-10® tablets (labeled claim: $10 \mathrm{mg} /$ tablet), were crushed and mixed using a mortar and pestle. The $182 \mathrm{mg}$ blend, equivalent to $10 \mathrm{mg} \mathrm{AT}$, was taken in three different $100 \mathrm{~mL}$ volumetric flasks and $20 \mathrm{~mL}$ of HPLC grade methanol was added to each flask. Each solution was sonicated for $10 \mathrm{~min}$ to effect complete dissolution of the AT calcium and the solutions were then made up to $100 \mathrm{~mL}$ with mobile phase and filtered through a 0.45 nylon membrane filter. A $1 \mathrm{~mL}$ of the filtered solution from each flask was transferred to three different $10 \mathrm{~mL}$ volumetric flasks and volume was made up to $10 \mathrm{~mL}$ with mobile phase, to yield a concentration of $10 \mu \mathrm{g} / \mathrm{mL}$

Analysis of AT in nanoemulsion formulation

The optimized nanoemulsion formulation was prepared in-house and contained Sefsol 218 and oleic acid (1:1), as an oil phase, tween 20 as a surfactant, carbitol as a co-surfactant and distilled water as an aqueous phase, along with $10 \mathrm{mg}$ of AT. To determine the content of AT in the nanoemulsion formulation (labeled claim: $10 \mathrm{mg}$ ), $1 \mathrm{~mL}$ nanoemulsion was suitably diluted with mobile phase to get $100 \mu \mathrm{g} / \mathrm{mL}$ stock solution. The solution was sonicated for $10 \mathrm{~min}$ and filtered with membrane filter. After appropriate dilution the drug content was analyzed in triplicate.

\section{RESULTS}

\section{Method Development}

\section{Development of mobile phase}

The selection of the solvent was based on sensitivity, ease of preparation, availability, and suitability for drug content estimation and of course cost of the solvent systems. A mobile phase consisting of $0.05 \mathrm{M}$ sodium phosphate $\left(\mathrm{NaH}_{2} \mathrm{PO}_{4}\right)$ buffer and methanol $(30: 70, \mathrm{v} / \mathrm{v}) \mathrm{pH} 4.1$ was optimized at a flow rate of $1 \mathrm{~mL} / \mathrm{min}$ for further studies after several preliminary investigatory chromatographic runs. Under the described experimental conditions, all peaks were well defined and free from tailing (Figure1).

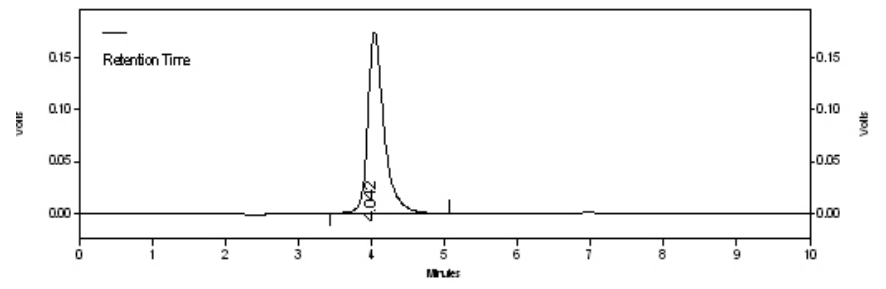

Figure 1. Typical HPLC chromatograms obtained from the analysis of AT in Bulk drug

\section{Optimized chromatographic conditions}

Chromatographic separation was achieved using a LiChrospherâ100 reversed-phase C-18 column $(250 \times 4.6 \mathrm{~mm})$ which was packed with $5 \mathrm{~mm}$ particles with a mobile phase consisting of $0.05 \mathrm{M}$ sodium phosphate buffermethanol $(30: 70 \mathrm{v} / \mathrm{v})$, adjusted to $\mathrm{pH} 4.1$ using o-phosphoric acid. The column oven was set at a temperature of $25 \pm 0.5^{\circ} \mathrm{C}$ and the mobile phase was filtered, degassed and pumped at a flow rate of $1.0 \mathrm{~mL} / \mathrm{min}$ with back pressure of 270 $\pm 4 \mathrm{kgf} / \mathrm{cm}^{2}$. The injection volume was $20 \mu \mathrm{L}$ and the total run time of each sample was $10 \mathrm{~min}$. The base line was continuously monitored during the process. The $\lambda_{\max }$ of AT was found to be $247 \mathrm{~nm}$, which was selected as the analytical wavelength for further analysis.

\section{Calibration curve}

The calibration curve was plotted between concentration and peak area and it was found to be linear over the concentration range of 0.125 to 100 $\mu \mathrm{g} / \mathrm{mL}$ with regression coefficient $\left(\mathrm{r}^{2}\right) 0.9997 \pm 0.0014(\mathrm{n}=3)$. The retention time and asymmetry factor were found to be $4.04 \pm 0.02 \mathrm{~min}$ and $1.05 \pm 0.03$ respectively.

\section{Validation of the method}

\section{Linearity}

The linearity was calculated by least squares linear regression analysis of calibration curve. The constructed calibration curve was linear over the concentration range of 0.125 to $100 \mu \mathrm{g} / \mathrm{mL}(\mathrm{n}=3)$. The linear regression equation was $Y=45351 x+4797.1$ with regression co-efficient of $0.9997 \pm$ 0.0014 . The mean value of slope and intercept were $45351 \pm 113.07$ and $4797.1 \pm 1641.53$ respectively with \% RSD values ranging from $0.3-1.15$ across the concentration range studied.

\section{Accuracy as recovery}

The proposed method afforded recovery of 99.94 to $101.63 \%$ after spiking the additional standard drug concentration to the previously analyzed test solution. The values of \% recovery, \% RSD and SE are shown in the Table 1 , in each case all the values for $\%$ RSD were found to be less than $1 \%$ which indicated that the proposed method was accurate and precise.

Table 1. Accuracy of the proposed method.

\begin{tabular}{|ccccc|}
\hline $\begin{array}{c}\text { Theoretical conc. } \\
\left(\boldsymbol{\mu g} \mathbf{~ m L}^{-1}\right)\end{array}$ & $\begin{array}{c}\text { Measured } \\
\text { conc. } \\
\left(\boldsymbol{\mu g} \mathbf{~ m L}^{-1}\right)^{\mathbf{a}}\end{array}$ & $\begin{array}{c}\% \\
\text { Recovery }\end{array}$ & $\begin{array}{c}\text { \% } \\
\text { RSD }\end{array}$ & SE \\
\hline $10(0 \%$ spiking $)$ & $9.99 \pm 0.07$ & 99.94 & 0.28 & 0.04 \\
$15(50 \%$ spiking $)$ & $15.00 \pm 0.10$ & 100.04 & 0.72 & 0.06 \\
$20(100 \%$ spiking) & $20.32 \pm 0.07$ & 101.63 & 0.36 & 0.04 \\
$25(150 \%$ spiking $)$ & $24.75 \pm 0.16$ & 99.03 & 0.66 & 0.09 \\
\hline
\end{tabular}

${ }^{a}$ Mean $\pm \mathrm{SD}, \mathrm{n}=3, \mathrm{SE}=$ standard error 
Precision and sensitivity

The intra- and inter-day variability or precision data is summarized in Table 2 . Low value $(<2 \%)$ of $\%$ RSD indicated the repeatability and precision of the proposed method.

Table 2. Precision of the proposed method $(n=3)$.

\begin{tabular}{|ccccccc|}
\hline $\begin{array}{c}\text { Conc. } \\
(\boldsymbol{\mu g} / \mathbf{m L})\end{array}$ & \multicolumn{2}{c}{ Repeatability (Intraday precision) } & \multicolumn{3}{c|}{ Repeatability (Interday precision) } \\
& Mean area \pm SD & SE & \% RSD & Mean area \pm SD & SE & \% RSD \\
\hline 0.05 & $21345 \pm 70$ & 40.41 & 0.32 & $20391 \pm 78$ & 45.03 & 0.38 \\
0.5 & $85251 \pm 579$ & 334.29 & 0.67 & $84333 \pm 601$ & 346.99 & 0.71 \\
5.0 & $688365 \pm 6009$ & 3469.96 & 0.87 & $678835 \pm 6122$ & 3534.64 & 0.90 \\
50.0 & $6861037 \pm 15473$ & 8933.64 & 0.22 & $6804321 \pm 16522$ & 9539.26 & 0.24 \\
\hline
\end{tabular}

Detection and quantification limits of the method were determined by standard deviation method as described in the experimental section. LOD and LOQ were found to be $0.20 \mu \mathrm{g} / \mathrm{mLand} 0.60 \mu \mathrm{g} / \mathrm{mL}$, respectively, indicated that the proposed method was highly sensitive.

Specificity

The specificity of the method was determined by exposing a solution of AT to stress conditions, i.e. $0.1 \mathrm{M} \mathrm{HCl}, 0.1 \mathrm{M} \mathrm{NaOH}$, and $3 \% \mathrm{H}_{2} \mathrm{O}_{2}$. AT was found to be more stable under acidic degradation conditions rather than under alkali stress conditions. The chromatograms obtained from AT after treatment with stress conditions are shown in Figure 2 to 4.
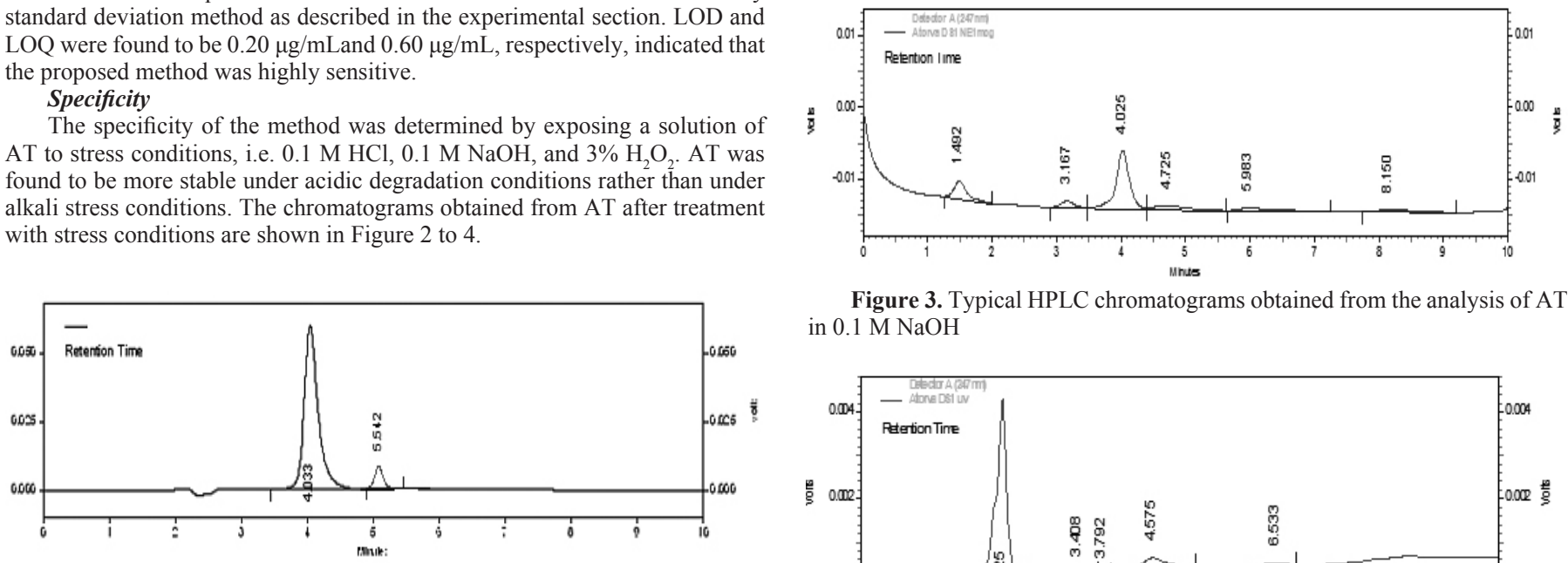

Figure 3. Typical HPLC chromatograms obtained from the analysis of AT in $0.1 \mathrm{M} \mathrm{NaOH}$

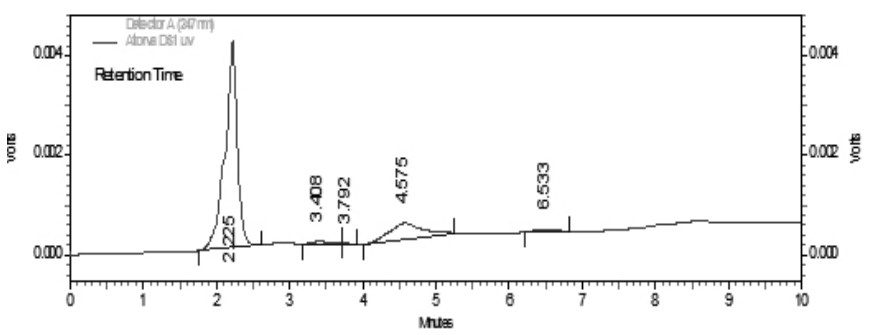

Figure 4. Typical HPLC chromatograms obtained from the analysis of AT in $3 \% \mathrm{H}_{2} \mathrm{O}_{2}$ Robustness

There was no significant change in the retention time of AT by changing the composition of the mobile phase, flow rate and pH of the mobile phase. The low value of the $\%$ RSD indicates the robustness of the method (Table 3).

Table 3. Robustness of the HPLC method $(\mathrm{n}=3$, Concentration $=10 \mu \mathrm{g} / \mathrm{mL})$.

\begin{tabular}{|c|c|c|c|c|c|c|c|}
\hline \multirow{2}{*}{ Parameters } & \multicolumn{3}{|c|}{ Study conditions } & \multirow{2}{*}{$\begin{array}{c}\text { Mean } \mathbf{R}_{t}{ }^{1}(\min ) \\
\pm \mathrm{SD}\end{array}$} & \multirow{2}{*}{$\% R_{t}$} & \multirow{2}{*}{ SE } & \multirow{2}{*}{$\begin{array}{c}\% \\
\text { RSI }\end{array}$} \\
\hline & Original & Used & Level & & & & \\
\hline \multirow{3}{*}{ Mobile phase } & \multirow[b]{3}{*}{$70: 30$} & $69: 31$ & -1 & $4.19 \pm 0.01$ & 104.22 & 0.005 & 0.23 \\
\hline & & $70: 30$ & 0 & $4.02 \pm 0.02$ & 100.00 & 0.011 & 0.49 \\
\hline & & $71: 29$ & +1 & $3.96 \pm 0.03$ & 98.50 & 0.017 & 0.75 \\
\hline \multirow{3}{*}{ Flow rate } & \multirow[b]{3}{*}{1.0} & 0.9 & -1 & $4.21 \pm 0.02$ & 102.93 & 0.011 & 0.47 \\
\hline & & 1.0 & 0 & $4.09 \pm 0.01$ & 100.00 & 0.005 & 0.24 \\
\hline & & 1.1 & +1 & $3.91 \pm 0.02$ & 95.59 & 0.011 & 0.51 \\
\hline \multirow{3}{*}{ pH } & \multirow[b]{3}{*}{4.1} & 4.0 & -1 & $4.03 \pm 0.04$ & 100.00 & 0.023 & 0.99 \\
\hline & & 4.1 & 0 & $4.03 \pm 0.01$ & 100.00 & 0.005 & 0.24 \\
\hline & & 4.2 & +1 & $4.01 \pm 0.06$ & 99.50 & 0.034 & 1.49 \\
\hline
\end{tabular}

${ }^{1}$ Retention time 


\section{Ruggedness}

There was no significant change in the mean area by comparison of the intra-day $(462459.7 \pm 10498.5)$ and inter-day assay $(438958.3 \pm 12463.4)$ result of AT that has been performed by two analysts in the same laboratory. The significantly low value of the $\%$ RSD $(<2 \%)$ indicates the ruggedness of the method.

Stability

The drug was stable when stored for 3 days at ambient temperature $(32 \pm$ $\left.1^{\circ} \mathrm{C}\right)$ and under refrigeration $\left(8 \pm 0.5^{\circ} \mathrm{C}\right)$ in optimized mobile phase. More than $98 \%$ of the AT remained unchanged, on the basis of comparison of peak areas with those obtained from a freshly prepared solution of AT.

\section{Application}

Assay of AT in marketed tablets

The validated method was applied for determination of AT in 20 commercially available Atolip- $10^{\circledR}$ tablets. Figure 5 illustrates a typical type of HPLC chromatogram of Atolip-10 $10^{\circledR}$ at a retention time $4.04 \pm 0.007$ with no interference of excipients commonly present in tablets. The results of the assay $(n=9)$ yielded $99.08 \%(\% R S D=0.56$ and $\mathrm{SE}=0.03)$ of labeled claim. The results of the assay indicate that the method is selective for the analysis AT without interference of the excipients.

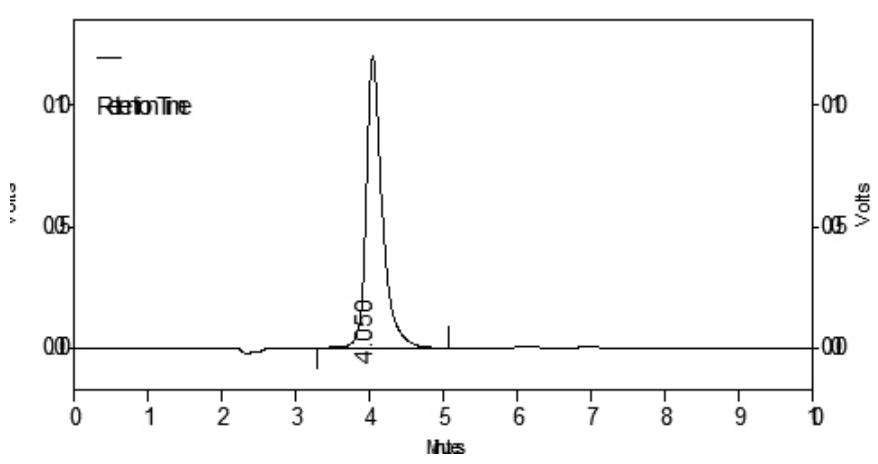

Figure 5. Typical HPLC chromatograms obtained from the analysis of AT in Atorlip-10® tablet II).

\section{Analysis of AT in nanoemulsion formulation}

A sharp peak was observed at the same retention time i.e. $4.033 \pm 0.014$ from the nanoemulsion formulation. There was no interaction between the AT and other excipients presents in the nanoemulsion formulation (Figure 6). The AT content was found to be $100.16 \%$ with $\%$ RSD of 0.53 . The low $\%$ RSD value indicates the suitability of this method for the routine analysis of AT.

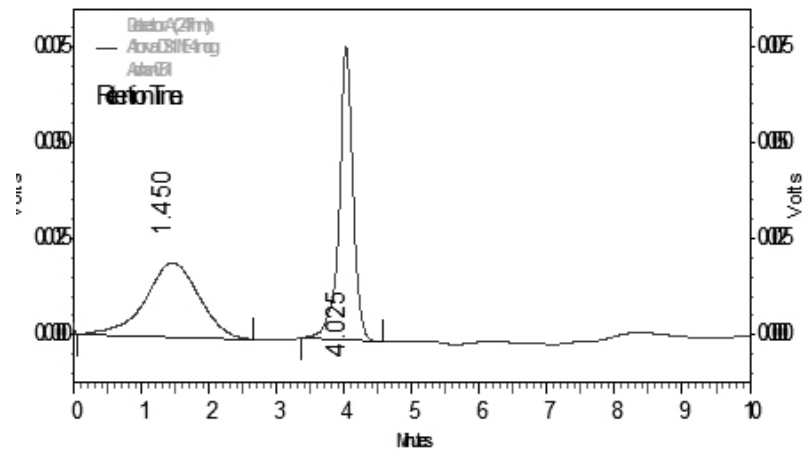

Figure 6. Typical HPLC chromatograms obtained from the analysis of AT in in-house prepared nanoemulsion.

\section{DISCUSSION}

In the present study, an attempt was made to develop a simple, accurate, selective and sensitive RP-HPLC method of AT in pharmaceutical analysis. LiChrospherÒ100, RP-18 column ( $5 \mathrm{~mm}$, RP-18 column, $250 \mathrm{~mm}$ x $4.6 \mathrm{~mm}$ i.d.), maintained at ambient temperature $\left(25 \pm 2{ }^{\circ} \mathrm{C}\right)$ was used for the method development. The method was validated for specificity, accuracy, linearity, precision (interday and intraday), sensitivity, robustness and ruggedness in accordance with ICH guidelines. The peak areas of the drug were reproducible as indicated by the low values of $\%$ RSD. The sample recoveries in formulation were in good agreement with their respective label claim which suggested noninterference of formulation excipients in the estimation. Also the $\%$ RSD for both the tablet analysis and recovery studies was less than $1 \%$ indicating high degree of precision of the proposed method. The effects of small deliberate changes in the mobile phase composition, $\mathrm{pH}$ and flow rate were evaluated as a part of testing for method robustness. The results indicated that the method is robust and is unaffected by small variations in the chromatographic conditions.

The results from stress testing, including separation of the degradation product and quantification of AT after exposure to stress conditions show the method is stability-indicating and capable of determining AT in presence of its degradation products. AT solution decomposed to $88 \%$ and $56 \%$ under acidic and alkaline stress conditions, respectively. In the presence of $3 \%$ $\mathrm{H}_{2} \mathrm{O}_{2}$, it was found that there was a substantial change in the peak area of AT (decreasing to $16 \%$ ). A degradation product eluted is noted in Figure 2 (peak 2 with a retention time of $5.5 \pm 0.05 \mathrm{~min}$ ) and another in Figure 4 (peak 1 with a retention time of $2.22 \pm 0.03 \mathrm{~min}$ ). The UV spectra of pure AT and undegraded AT were compared and found to be similar with regard to $\lambda_{\max }$ and appearance. This indicated the specificity of the method.

This method is based on the previously reported procedures ${ }^{12,15,19}$ but represents an analytical advancement that it is applicable for in vitro samples. A simple mobile phase without addition of any ion-pairing agents and a short run time are advantageous and make this method suitable for routine analysis of large number of samples per day.

\section{CONCLUSIONS}

A simple, rapid, highly sensitive, accurate and stability indicating RPHPLC analytical method has been developed and validated as per the ICH guidelines. Based on the statistical analysis of the data it has been unequivocally construed that the method is reproducible and selective for the routine analysis of AT in bulk drug, tablet dosage forms and nanoemulsion formulation.

\section{ACKNOWLEDGEMENTS}

The authors are highly grateful to Lupin Ltd., Pune, India and Arbro Pharmaceuticals, Delhi, India, for providing the drug gift samples.

\section{REFERENCES}

1. N. Jain, R. Raghuvanshi, D. Jain, Ind. J. Pharm. Sci. 70, 263, (2008).

2. A.P. Lea, D. McTavish, Drugs 53, 828, (1997)..

3. S. Shafiq, F. Shakeel, S. Talegaonkar, F.J. Ahmed, R.K. Khar, M. Ali, Eur. J. Pharm. Biopharm. 66, 227, (2007).

4. F. Shakeel, S. Baboota, A. Ahuja, J. Ali, S. Shafiq, J. Nanobitech. 6, E8, (2008).

5. F. Shakeel, S. Baboota, A. Ahuja, J. Ali, S. Shafiq, J. Drug Target. 16, 733, (2008).

6. N. Erk, Anal. Lett. 36, 2699, (2008).

7. L. Novakova, S.A. Lopez, D. Solichova, D. Satisky, B. Kulichova, A. Horna, P. Solich, Talanta 78, 834, (2009).

8. S.S. Yadav, D.V. Mhaske, A.B. Kakad, B.D. Patil, S.S. Kadam, S.R. Dhaneshwar, Ind. J. Pharm. Sci. 67, 182, (2005).

9. W.W. Bullen, R.A. Miller, R.N. Hayes, J. Am. Soc. Mass Spectrom. 10, 55, (1999).

10. M. Jemal, Z. Ouyang, B.C. Chen, D. Teitz, Rapid Commun. Mass Spectrom. 13, 1003, (1999).

11. A.G. Altuntas, N. Erk, J. Liq. Chromatogr. Rel. Technol. 27, 89, (2004).

12. G. Bahrami, B. Mohammadi, S. Mirzaeei, A. Kiani, J. Chromatogr. B. Analyt. Technol. Biomed. Life Sci. 826, 41, (2005).

13. M. Hermann, H. Christensen, J.L. Reubsaet, Anal. Bioanal. Chem. 382, $1242,(2005)$

14. V. Borek-Dohalsky, J. Huclova, B. Barrett, B. Nemec, I. Ulc, I. Jelinek, Anal. Bioanal. Chem. 386, 275, (2006)..

15. R. Nirogi, K. Mudigonda, V. Kandikere, J. Pharm. Biomed. Anal. 44, 379, (2007).

16. S. Erturk, A.E. Sevinc, L. Ersoy, S. Ficicioglu, J. Pharm. Biomed. Anal. 33, 1017, (2003).

17. B.G. Chaudhari, N.M. Patel, P.B. Shah, Chem. Pharm. Bull. 55, 241, (2007).

18. M.K. Pasha, S. Muzeeb, S.J. Basha, D. Shashikumar, R. Mullangi, N.R. Srinivas, Biomed. Chromatogr. 20, 282, (2006). 
19. A. Mohammadi, N. Rezanour, D.M. Ansari, B.F. Ghorbani, M. Hashem, R.B. Walker, J. Chromatogr. B. Analyt. Technol. Biomed. Life Sci. 846, 215, (2007).

20. D.A. Shah, K.K. Bhatt, R.S. Mehta, M.B. Shankar, S.L. Baldania, T.R. Gandhi, Ind. J. Pharm. Sci. 69, 546, (2007).

21. T. Shivakumar, R. Manavalan, C. Muralidharan, K. Valliappan, J. Sep. Sci. 30, 3143, (2007).

22. Ismail, R. Rajavel, M. Ganesh, M. Jgadeeswaran, K. Srinivasan, J. Valarmathi, T. Shivakumar, Asian J. Res. Chem. 1, 40, (2008).

23. U. Seshachalam, C.B. Kothapally, J. Liq. Chromatogr. Rel. Technol. 31, $714,(2008)$.

24. X.S. Miao, C.D. Metcalfe, J. Chromatogr. A. 998, 133, (2003).

25. R.P. Shah, V. Kumar, S. Singh, Rapid Commun. Mass Spectrom. 22, 613, (2008).
26. H.R. Shen, Z.D. Li, M.K. Zhong, Pharmazie 61, 18, (2006).

27. H. Shen, M. Zhong, J. Pharm. Pharmacol. 58, 1183, (2006).

28. A. Zarghi, A. Shafaati, S.M. Foroutan, A. Khoddam, Arzneimittelforschung. $\mathbf{5 5}, 451,(2005)$

29. B. Stanisz, L. Kania, Acta Pol. Pharm. 63, 471, (2006).

30. International Conference on Harmonization (ICH) of technical requirements for registration of pharmaceuticals for human use: Harmonized Triplicate Guideline on Validation of Analytical procedures: Methodology (November 1996) ICH Steering Committee IFPMA, Switzerland

31. M. Zaxariou, I. Panderi, J. Pharm. Biomed. Anal. 35, 41, (2004). 